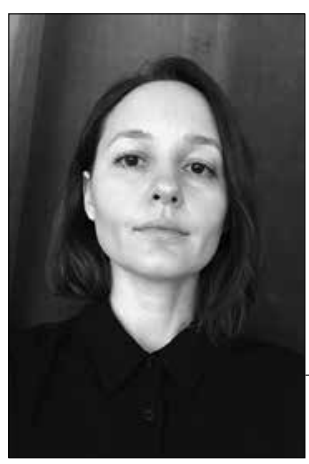

https://doi.org/10.24101/logos.2017.40

Gauta 20170311

ERNESTA PAUPLIENÉ

Vilniaus dailès akademija, Lietuva

Vilnius Academy of Arts, Lithuania

\title{
GROŽIO PAIEŠKOS NETOBULUME TRADICINĖJE JAPONŲ KERAMIKOS ESTETIKOJE: KINTSUGI
}

\author{
Finding Beauty in Imperfection \\ in the Traditional Japanese Ceramics Aesthetics
}

\begin{abstract}
SUMMARY
The article focuses on kintsugi, aka kintsukoroi, the original, traditional way of repairing broken pottery. This tradition has been inspired by the uniqueness of Japanese Zen aesthetics and the concept of beauty. In order to analyze the topic, it is important, firstly, to summarise the distinguishing features of the ascetic beauty concept. The roots of this concept lie in the Japanese aesthetic tradition. This tradition significantly differs from the fundamental classic beauty ideals of the West. The natural character and simplicity of a pottery form acquires an exceptional aesthetic value, From the point of view of the supporters of the Japanese traditional aesthetics, the traces of past times on a pottery vessel enrich the object with new associations. The crack subconsciously reminds viewers of the constant earthquakes in Japan, eruptions of volcanoes, floods or ruthless and destructive wars. The beauty ideals so different from the ones of the Western culture have become exceptionally relevant in postmodern Western art, which has focused anew on the various, previously peripheral non-classical forms of aesthetics and art.
\end{abstract}

\section{SANTRAUKA}

Šiame straipsnyje daugiausia dèmesio skiriama japonų dèl dzen estetikos ir grožio sampratos ypatingumo susiformavusiai savitai tradiciniam skilusios keramikos taisymo būdui - kintsugi arba dar kitaip vadinamam kintsukoroi. Norint tai padaryti, iš pradžiu svarbu glaustai aptarti japonų estetikos tradicijoje susiformavusius savitus asketiškos grožio sampratos ypatumus, kurie smarkiai skiriasi nuo pamatinių Vakarų klasikinės grožio sampratos idealų. Keramikos dirbinio formos natūralumas ir paprastumas čia igauna išskirtinę estetinę vertę, o keramikos kūrinyje išlikę laiko pẻdsakai japonų tradicinės estetikos šalininku požiūriu tik 
praturtina naujų asociacijų meno kūrinį, kadangi jo ịskilimas, sutrūkimas iškart pasąmonėje sukelia minčių apie nuolat Japonijos salas purtančius žemės drebėjimus, ugnikalnių išsiveržimus, potvynius ar nuožmius destruktyvius karus. Šios nuo Vakarų kultūros grožio idealų besiskiriančios ypatybės ypač aktualios dabartiniame postmoderniame Vakarų mene, kuriame atgimsta dėmesys įvairioms anksčiau paribiuose buvusioms neklasikinèms estetikos ir meno formoms.

„Kelionè, tapusi pernelyg lengva ir patogia, praranda savąji dvasingumą. ${ }^{\text {}}$

(Daisetz Teitaro Suzuki)

Dabartinejje Vakarų estetikoje ir mene dèl „postmodernaus orientalizmo" poveikio pradèta itin domètis ịvairiais neklasikiniais Rytų Azijos kultūrose susiformavusiais estetiniais idealais ir meninès kūrybos formomis. Šiuo aspektu Vakarų taikomosios dailès specialistus vis labiau domina ilgai akademinès menotyros periferijoje buvusios rafinuotos kinų ir ypač japonų keramikos tradicijos, kurių savitumas iškart išryškejja lyginant su Vakarų keramikoje vyraujančiais estetiniais principais ir grožio idealais.

Pastaraisiais šimtmečiais Vakaruose isigalëję i išorini groži orientuoti klasikinès estetikos principai smarkiai skiriasi nuo tu, kuriuos regime tradicinejje japonu estetikoje ir mene, kur estetinių požiūrių savitumą stipriai paveikè šintoizmo ir dzen estetikos tradicijos, kurios didžiausią reikšmę grožio sampratoje skyrè neryškumui, santūrumui, paprastumui, asimetrijai, medžiagos, iš kurios daromas meno kūrinys, natūralių faktūrų grožiui.

Lyginant Vakaru grožio sampratą su savita japonų dzen estetika, matyti, kiek daug susižavëjimo išoriniais dalykais, standartizuotomis ir kanonizuotomis antikos ir renesanso meno formomis, egocentriškumo ir antropocentrizmo yra vakarietiškoje kultūroje. Vakaruose grožis yra didingas ir demonstratyvus. Čia itin svarbus erdvės užpildymas vaizdais ir garsais, kad žmogaus sąmonè, orien- tuota $\mathfrak{i}$ " aš", nepajustų vienatvès ir dvasinio alkio. Jis yra patogus vartoti ir turintis aiškų galiojimo laiką.

Graikijoje ilgą laiką grožis siejosi su tobulumu, naudingumu ir morale, kitaip tariant, su tuo, kas yra gerai. O Rytų Azijos mąstymo tradicijoms ,....svetimas gèrio ir blogio, grožio ir bjaurumo supriešinimas, kadangi, priklausomai nuo konkretaus atvejo ir situacijos, tarp jų gyvuoja daugybè sudètingiausių tarpinių būsenų, kartais netgi viena priešybè natūraliai gali perimti kitos funkcijas. Pavyzdžiui, subanalintas grožis gali virsti banaliu, tada jis vadinasi bjaurumu, o gilus ir išraiškingas bjaurumo apraiškų perteikimas gali igauti grožio funkcijas ir pan."2

Japonų kultūroje grožio sąvoka labiau vartotina vidinių išgyvenimų raiškai, dvasiniam nušvitimui apibūdinti, o menas neatsiejamas nuo kasdienybės ir nèra ribos, kuri skirtų meną nuo amato. Vietinè tradicinè religija šintoizmas ir iš Kinijos atkeliavęs dzenbudizmas turbūt labiausiai paveikè japonų estetikos pagrindą. Japonams ypač būdingas artimas santykis su gamta, dermè su aplinka. Kiekvienas daiktas ir veiksmas čia turi savo sezoniškuma, sutampanti su gamtos ritmu. Tiesa gali atsiskleisti stebint gamtos virsmus: nieko nèra amžino, tobulo, užbaigto.

Japonų estetikos idealus nusakančios kategorijos gana sunkiai randa atitikme- 
nis kitose kalbose. Vienos dažniausiai pasitaikančiu - wabi, sabi ir shibui - turtingos savo prasmèmis ir užuominomis, kartu sukuria gilu dvasini, estetini ir psichologini, santyki su menu. Wabi estetine kategorija nurodo skurdo, stokos pozityvumą ir iš jo kylančią ramybę, tyla, vienišuma, kukluma, nuolankuma, santūrumą, asimetriją ir elegantišką paprastumą. Sabi žymi susidevejjimą ir laiko apnašas, tęstinuma, istorija, praradimo jausmą, vienatvę ir melancholiją. Shibui nusako susilaikyma, santūrumą, neišsakymą, kukluma, giedra, ramybę, rafinuotą paprastumą bei kilnų asketizmą. Grožis dzen estetikoje yra intuityvus ir spontaniškas, ir suprantamas remiantis šiomis glaudžiai susijusiomis, viena kitą papildančiomis kategorijomis, kurias išties sunku atskirti.

Minètos estetinès kategorijos ragina kontempliuoti savo paties laikinuma, pasinerti $\mathfrak{i}$ egzistencinị vienišumą ir atsiduoti švelniam liūdesiui. Gyvenimo neapibrèžtumas, netiketumo momentas čia vertinamas kaip ypatinga vertybè, igalinanti stebètis ir pažinti.

Hisamatsu Shin'ichi išskiria septynias japonu dzen meno ypatybes: asimetrija, paprastumas, asketiškas kilnumas, natūralumas, subtilus išmintingumas, neprisirišimas ir ramybè.

Grožis dzen estetikoje siejamas su santūrumu, jis, galima sakyti, nebylus ir slèpiningas. Jis tarsi virsmas, kelias, vedantis nuo netobulybės i j jos priešingybę. Subtilus grožio pajautimas slypi asimetrijoje, askezèje, susitaikyme. Tokios priešybès, kaip, tarkim, grubi vaza ir i ją pamerkta trapi lauko gèlè, estetu pasitelkiamos sukurti užuominą apie pačią grožio prigimti. Taip pat itin vertinamos laiko apnašos ant rafinuotų meno kūrinių kaip sugestyvaus grožio apraiška. Sutrūkę, netekę blizgesio, nuo naudojimo nugludinti daiktai atliepia mumyse mūsų pačių trumpaamžiškumą ir kartu žadina permanentinès būties ịvairovès vaizdinius. Atmetus išankstines nuostatas ir lūkesčius, iš karto pastebėsime, jog kiekvienas daiktas, kad ir koks tvirtas būtur, tèra pastovumo iliuzija. Visa, kas pakyla iš dulkiu, anksčiau ar vèliau i jas sugrị̌s. Japonams artimas gilus daiktų prigimties pajautimas, jausmingas intymumas.

Sakoma, kad Sen no Rikyū, vienas iškiliausių XVI a. arbatos meistru Japonijoje, pirmasis paprastai bambuko vazai suteikè ypatingą meninę reikšmę. Ir pirmoji tokia vaza buvo pavadinta Onjoji. Netgi tada, kai ji įskilo ir pradejjo šiek tiek leisti vandeni, tai buvo vertinama kaip natūralus procesas, gražus ir vaizdingas pats savaime. Vienos arbatos ceremonijos metu svečiui pastebejjus, kad tos vazos, stovinčios tokonomoje, apačioje renkasi vanduo, jam buvo atsakyta, kad tai ir yra pati vazos esmé3. Taigi, galima manyti, kad tik įskilusi toji vaza ir mažas vandens telkinys iš jos atvèré kelią gilesniam, kontempliatyviam žvilgsniui, estetiniam natūraliu procesu išgyvenimui.

Kaip kad nieko nèra tobulo, taip ir grožis, anot D. T. Suzuki, ,....nebūtinai žavi tobula forma. Viena iš esminiu japonų menininkų ypatybių - įkūnyti groži netobulume ar net bjaurume. ${ }^{44}$ Vedini giliu ižvalgu japonų menininkai grožio apraiškų ieško dar prieš joms pasirodant, tarsi siekdami užčiuopti tai, kas yra tarp tobulybės ir jos priešybès, tarp gyvybès ir mirties. Regėdami besiskleidžianti žiedą mes galime išgyventi tapsmą. Taip 
pat galime suvokti duotybę, matydami, kaip žiedas nyksta. Tai nuolat kintantis reiškinys, kupinas spontaniškumo ir nenuspejjamumo. Svarbiausias čia yra procesas, judesys, nes tik ji pažinę, pažinsime pirmapradi būvì, ir todèl simetrija ir išbaigtumas niekaip neatitinka japonų grožio sampratos.

Kita vertus, asimetriškumo išaukštinimas nepanaikina universalaus harmonijos principo, kuris tiesiogiai siejasi su Visatos harmoniškumo idejja. Harmonija - pirmapradė pasaulio būsena. Viskas gamtoje paklūsta visa aprépiančios harmonijos dèsniams, ir asimetriškumas šia prasme tampa aukštesne pastarosios pasireiškimo forma. Menininko tikslas - pastebèti ir parodyti šią harmoniją. ${ }^{5}$

Formos paprastumas ir joje palikti laiko pèdsakai dzen estetikoje labiau praturtina meno kūrini, nei ji naikina. Iskilimas, sutrūkimas gali byloti apie nuolat Japonijos pusiasali purtančius žemès drebejjimus bei kitas gamtos bei žmonijos stichijas: ugni, potvynius ar karus. Atsisakydami teatrališko demonstratyvumo, atsitraukime ir tyloje, neneigdami ir nesipriešindami galime išgyventi prigimties esmę, kuriančios ir griaunančios Visatos grožį. Leisti dvasiai tyliai kontempliuoti savo pačios esatị. Santūriai ir kartu išdidžiai priimti negandas ir tenkintis asketišku būviu pagarbos pilna širdimi. „Iš tikrujuu dzen estetikoje skilimas yra esminė žymè, vieta, kur susitinka žmogaus ir ne žmogaus jègos, apjungiančios materialius atsitiktinumo efektus su iš anksto apgalvotais estetiniais sprendimais." 6

Atsitiktinumas keramikoje byloja apie tai, kad yra daugelis veiksniu, lemiančiu ivykius, ir gebejjimas su jais susitaikyti bei juos vertinti kaip ypatingą duotybę prilygsta savojo ego atsižadèjimui ir nuolankiam Visatos désnių prièmimui. Tai tarsi menininko ir nuo žmogaus nepriklausomų gamtos veiksnių bendras kūrybinis projektas. Keramikos indas šiuo atveju yra penkių kosminiu elementų dermé - ugnies (degimas), medžio (pelenai), žemès (molis), metalo (glazūra) ir vandens (aušinimas) sajunga. Ir tik nuraminęs savo klaidžiojanti prota, peržengęs formą ir pajutęs dvasią kūrèjas gali šias jègas sutelkti i harmoninga visumą. Tai kartu ir didžiulis darbas su savimi pačiu - pasiekti formai neprieraišų sąmonės būvị.

Japonų keramikoje išskiriami tam tikri skilimai, nutinkantys kūrybos proceso metu „....pradedant glazūros skilinèjimu ant daugybès įvairaus tipo keramikos, ypač seladono, ir baigiant smulkiausiais skilinejjimais, traukiantis moliui apie mažus akmens gabalèlius (ishiha$z e)$ - efektas itin vertinamas Shigaraki keramikoje, ir nuo plauko storumo linijų, ir smulkių skilinejjimų iki kiaurai permatomų plyšių, net žiojèjančių skylių, atsirandančių nuo stiprios erozijos. ${ }^{\text {"7 }}$ Yra daugybè terminu, skirtų ivardinti tokius įtrūkimus: kire, hibi, ware, yamaware, shinshoku ${ }^{8}$. Dèl šiu atsitiktinumų keramikos arbatos dubenèliuose itin ryškiai atsiskleidžia gamtos paveikslas. Jei paimtume vakarietišką arbatos puodeli, kad ir iš kurios pusės pažiūrètume, jis yra labai aiškus ir nuspejjamas, o japonų arbatos dubenèliai savo asimetriška forma, tekančia, kraklëjančia glazūra ir atsitiktinumo ženklais yra tarsi nuolat kintantys, niekada nežinai, ką pamatysi pažvelgęs kitu kampu, kitoje šviesoje. Svarbu, kad glotnus būtų dubenèlio vidus ir kraštelis, o išorè gali varijuoti skirtingomis faktūromis sužadindama ịvairius lytėjimo 
pojūčius. Pirštu galiukais mes galime leistis į kelionę po įstabaus grožio Japonijos kalnus, tada nuklysti i pievas ar panerti i vandenis, supančius salyną, užčiuopę skilimą galime pajusti gamtos stichiju galią. Spalviniai sprendimai subtiliai priderinami prie metu ar net paros laiko. Dubenèlis tarsi Visatos ir jos nuolatinio vyksmo simbolis, mūsų pačiu prigimties ivvaizdinimas.

\section{KINTSUGI GROŽIO SAMPRATOS SAVITUMAS}

Kintsugi yra toks procesas, kurio metu ískilusi, nuskilusi ar sudužusi keramika sujungiama naudojant urushi (lako) ir ryžiu klijus. Urushi gaminamas iš tam tikro penkiolikos metų senumo medžio sulos, kuri sukietèja gavusi deguonio'. „Sula, skleidžianti itin nuodingus garus, ore igauna rusvą atspalvị ir kartu sukietèja tiek, kad tampa tokia kieta ir stipria medžiaga, kurią galima poliruoti, drožinèti ar net modeliuoti kokią nors formą. ${ }^{10}$ Iš vieno medžio išgaunama 200 gramu urushi ${ }^{11}$.

Kishōmi urushi („grynas lakas“) yra pagrindas visu darbu, kai naudojamas lakas suklijuoti tiek originalias duženas (tomotsugi), tiek didesnes trūkstamas dalis pakeičiant naujomis (yobitsugi) ar ịterpiant medžio plokšteles (mokuhen). Tai aukštos kokybès natūralus lakas, kuri sumaišius su ryžiu klijais gaunamas nori urushi (kliju lakas) - itin lipni ir greitai džiūstanti (per kelias dienas) medžiaga. Pastaruoju metu pradètas naudoti mugi urushi - kishōmi urushi, sumaišytas su miltų klijais. Masė tokia pat lipni, bet džiūvimo procesas kur kas ilgesnis - iki dešimties dienu $u^{12}$. Sujungimas dar padengiamas 23 karatu aukso ar kito metalo dulkèmis, kartais, kada jos visai susijungia su laku ir sutingsta, kad igautu žvilgesio, įtrinamos šilkiniu audiniu ir padengiamos vienu permatomo lako (suki urushi) sluoksniu. Iš esmès kintsugi kaip atskira meno sritis neegzistuoja. Procesas paprastai atliekamas panašaus amato specialistu. Dengimo laku technika Japoniją pasiekè iš Kinijos per Korejąa kartu su budizmu VI a. viduryje. Maki-e - tokia technika, kada daikto paviršius kuriamas ji apšlakstant arba apipurškiant šlapiu laku ir padengiant aukso, sidabro ar kito metalo dulkèmis bei ịvairiu spalvų milteliais. Tam naudojami dulkių vamzdeliai, purkštuvai (makizutsu) ar natūralių šeriu teptukai. Procesas trunka iki keliolikos dienų. Pradèta naudoti Heian periodu (794-1185) širmu, albumu, inrō (tradicinè japonų dėžutè smulkiems daiktams, rišama prie kimono juostos), laiškų dèžučiu ir rašalo plokšteliu dèklų puošybai, ši technika itin išpopuliarèjo Muromachi periodu (139-1573). Šio laikotarpio amatininkai pasiekẻ toki aukštą technikos lygi, kad pas juos vykdavo mokytis net iš pačios Kinijos.

Meniniai restauravimo laku aspektai daugiau ar mažiau priklausė nuo estetikos pajautimo, sietino su meistru ir dirbtuvèmis. Muromachi periodu pretenzingas dzen estetikos paprastumas skleidèsi aukštos kokybės juodos spalvos lako paviršiuje su minimaliu arba visai be jokio dekoro. XVI a. antroje puseje tarp japonu karių elito pradejo plisti „dekoratyvioji estetika“"13. „Šiai estetikai būdin- 
ga gausiai ir ryškiai naudoti aukso ir sidabro aplikacijas. Prasidejjus Edo periodui (1603-1868), ji pamažu èmè kisti ir igavo daugiau santūrumo, kuris labiau atspindejjo rafinuotą klasikinį skoni. Puikiai ši stilių reprezentuoja Hon'ami Kōetsu (1556-1637), japonu amatininko, keramiko, lako meistro ir kaligrafo, žinomo kaip vieno geriausiu arbatos meistro Furuta Oribe mokinių, aistra fūryū (estetiniam rafinuotumui) ir suki. Pastarasis terminas dabar verčiamas kaip „meninis skonis", bet XVI a. jis taip pat visu pirma reiškė „meilè rafinuotam menui“. Kitas pavyzdys yra kirei sabi, „elegantiška patina", būdinga arbatos meistro Kobori Enshu (1579-1647), simpatizavusio estetiniams idealams, darbams, atspindejusiems puikų mistikos ir elegancijos balansą. Šie du pavyzdžiai anaiptol neatskleidžia viso šios pamatinès estetikos spektro. Jos užuomazgu galima rasti ir asobi estetiniuose idealuose, kuriuos pirmą kartą panaudojo Furuta Oribe (15441615) kaip aliuziją i žaidimą, malonuma, pramogas. Tokiu būdu sukurdavo kontrastą itin asketiškoms estetinėms kategorijoms sąmoningai siekdamas žaismingo kūrybiškumo ir îvairovės. Iš čia atsirado gerokai laisvesnis, žaismingesnis restauravimas laku, daugiau improvizacijos ir jausmingumo. Kintsugi ištakos siekia Muromachi periodą. Kartą Japonijos šiogūnas Ashikaga Yoshimitsu (1358-1408) sudaužė savo mėgstamą arbatos dubenèli ir labai dèl to susikrimto. Jis išsiuntè ji pataisyti i Kiniją. Gavęs dubenèli atgal, šiogūnas didžiai nusivylè grubiu duženų sujungimu metalinèmis sąsagomis. Vietos meistrams teko sugalvoti subtilesni taisymo būdą.

Istorija apie karo vado Toyotomi Hideyoshi (1537-1598) mègstamiausią korejuu ido stiliaus arbatos dubenèli rodo, koks stiprus įkvejpimo šaltinis yra griaunanti jèga ir kaip subtiliai ji pereina i kūrybą. Vieno susirinkimo metu Toyotomi Hideyoshi tarnas netyčia numetè dubenèli ir jis suskilo i penkias dalis. Visi, buvę šalia, žinodami, kokio ūmaus būdo yra Hideyoshi, sustingo iš baimès. Bet vienas iš svečių - Hosokawa Yusai leido sau paimprovizuoti šio ivvykio tema perkurdamas gerai žinomos tuo metu poemos posmeli. Toks netikètas poelgis sušvelnino Hideyoshi pykti. Vèliau dubenèlis buvo sutaisytas, pavadintas Tsutsui Zutsu-Ido vardu ir tebesaugomas kaip svarbus kultūrinis paveldas ${ }^{14}$.

Arbatos ceremonijose visi indai, įrankiai buvo kruopščiai šeimininko parenkami atsižvelgiant i svečius, metų laiką. Jie buvo tarsi užslèptos nuorodos nuotaikai ir pokalbių temai, skirtingus meistrus ir jų stilistiką reprezentuojantys simboliai. Arbatos meistrai tikèdavosi, kad ju daiktai juos pergyvens ir, naudojami kitų, primins jų istorijas. Todèl senëjimo ženklai ar atsitiktinumas, paveikęs objekto vaizda, vertinti kaip itin savitos, nepakartojamos istorijos dalis, perduodamos iš kartos i kartą. Požiūris i defektus, netobulumus, trūkumus atspindi ypatingą japonų estetikos suvokimą, kuriam būdinga gili įžvalga ir jautrumas. Laikinumo suvokimas atveria daiktų esmès patyrimo ir intuityvaus pažinimo nepaliaujamą skleidimąsi.

Turintys ilgą istoriją bei itin arbatos ceremonijose vertinami daužti arbatos dubenèliai jose naudojami tik paskutines dvi lapkričio savaites ${ }^{15}$.

Arbata, pirmą kartą patiekta lygiai prieš metus, baigiasi. Ir nors tirštos arbatos teužtenka trims, kviečiami penki svečiai. Su dideliu dèkingumu ir pagarba jie žino, 
kad arbatos, likusios dar nuo šių metú, patiektos viename dubenèlyje, pasimègauti užteks visiems. Tai stipriausia nagori išraiška - nepaprastai gražus bendruomeninis impulsas branginti ir dalintis tuo, kas liko. ${ }^{16}$

Kaip ir dužęs arbatos dubenèlis, iš naujo sukurtas iš to, kas liko.

Vienas puikiausių arbatos dubenèliú, anot kai kurių arbatos praktikuotoju yra IX a. ryžiu dubenèlis iš Korèjos, žinomas kaip Kizaemon-Ido, kuris savo paprastumu ir asketiškumu puikiai atskleide arbatos meno esmę. Metams bėgant, laikas palikdavo jame vis daugiau pèdsaku, jis buvo vis pataisomas, bet tai ne tik kad nepaveikè jo estetinio vaizdo, bet dargi ji ir praturtino. Ilgainiui arbatos mene tai tapo tam tikra manierizmo for$\mathrm{ma}^{17}$. Skilimai, susidèvejjimas būdavo išryškinami subtiliu apipavidalinimu išryškinant ir pabrèžiant jų savitumą. Dūžimas tapo neišvengiama duotybe, kurios neneigiant buvo siekiama kūrybiško sprendimo. Iš čia skleidžiasi formos kaip galutinès ir išbaigtos neigimas, toks būdingas japonų dzen estetikai. Forma yra kintanti. Beformiškumas yra aukščiausia formos apraiška. Todèl arbatos dubenèlio forma turi būti laisva, asimetriška ir natūrali, o dūžimas tèra judesio, kuriam turime būti dèkingi už esatí, padarinys. Ir skilimo padengimas auksu ar kitu metalu čia turi aiškią simbolinę prasmę - tai permanentinès būties sutaurinimo simbolis.
Taip pat pradètas vertinti ne tik atsitiktinumas, bet ir sąmoningas, gerai apgalvotas veiksmas, kurio metu kūrinys būdavo pakoreguojamas tokių iškilių arbatos meistru kaip Furuta Oribe, Sen no Rikyū ir kitų.

Furuta Oribe griovè ir plètè iprastas dizaino ribas. Ižvelgdamas groži trūkume ir asimetrijoje, jis arbatos ceremonijoms rinkdavosi būtent tokias estetines savybes turinčius daiktus. Kartu nevengè pats suteikti tokių savybių "pernelyg tobuliems" juos daužydamas ar kitaip pažeisdamas ${ }^{18}$, taip tarsi sukurdavo nuorodas i apgaulingą prieraišuma, trukdanti pažinti pirmapradị būvị. Stokojanti arba netobula forma kreipia dèmesi i vidinius išgyvenimus, žadina gilaus pažinimo siekị.

Kita istorija pasakoja apie tai, kaip arbatos meistras Takeno Jōō (1502-1555), eidamas kartu su Sen no Rikyū, vienoje parduotuvės vitrinoje pastebejjo puikią vaza, nors ir pernelyg simetrišką savo puošniomis vienodomis ąselemis. Jis nieko nepasakè, manydamas vèliau sugrižti ir ją issigyti. Deja, Rikyū, turèdamas toki pati plana, buvo greitesnis. Praejuus kiek laiko Jōō buvo pakviestas Rikyū ì arbatos ceremoniją. Tikèdamasis, kad ten bus ir toji vaza, jis paslèpé plaktuką savo kimono planuodamas nudaužti vieną ąselę. Jam atvykus, vaza stovejo tokonomoje jau be ąselès. Ir vèl Rikyū buvo pirmesnis, jis pats sugriovè simetrija, o pažeista vieta glotniam paviršiui suteikè subtilaus žavesio ${ }^{19}$.

\section{IŠVADOS}

Taigi galima teigti, kad dzen estetikos principais besivadovaujantys arbatos meistrai sąmoningai atmesdavo tobulybę kaip galutinę ir neginčytiną tiesą. Mat tobula forma kreipia dėmesi tik į išorinę forma, už jos daugiau nieko nèra, ji ne- 
palieka peno vaizduotei. Žmogus, kamuojamas neramaus, nuolat vertinančio proto, yra priklausomas nuo išoriniu aplinkybių. O susitelkimas ị dvasinius, esminius dalykus leidžia nepaisyti formos. „....japonu menininkai, daugiau ar mažiau paveikti dzen, savo jausmus linkę išreikšti vartodami kuo mažiau žodžiu ar teptuko potepių. Kada jie [jausmai] pernelyg išreikšti, nebelieka vietos

\section{Literatūra}

Allen S. Weiss, Zen Landscapes: Perspektives on Japanese Gardens and Ceramics. London: Reaktion Books, 2013.

Allen S. Weiss, The Grain of the Clay-Reflections on Ceramics and the Art of Collecting. London: Reaktion Books, 2016.

Antanas Andrijauskas, Tradicine japonu estetika ir menas. Vilnius: Vaga, 2001.

Charly Iten, Ceramics Mended with Lacquer - Fundamental Aesthetic Principle, Techniques and Artistic Concepts. The Aesthetics of Mended Japanese Ceramics. New York: Herbet F. Johnson Museum of Art, Cornell University, 2008.

\section{Nuorodos}

11 Daisetz Teitaro Suzuki, Zen Buddhism and its influence on Japanese culture. Kyoto: The Eastern Buddhist Society, 1996, p. 145.

12 Antanas Andrijauskas, Neklasikines ir postmodernistines filosofijos metamorfozès. Vilnius: Meno rinkos agentūra, 2010, p. 574.

13 Allen S. Weiss, Zen Landscapes: Perspektives on Japanese Gardens and Ceramics. London: Reaktion Books, 2013, p. 139.

14 Daisetz Teitaro Suzuki, p. 17.

15 Antanas Andrijauskas, Tradicine japonu estetika ir menas. Vilnius: Vaga, 2001, p. 155.

16 Allen S. Weiss, p. 139.

17 Ten pat, p. 141.

18 Allen S. Weiss, The Grain of the Clay-Reflections on Ceramics and the Art of Collecting. London: Reaktion Books, 2016, p. 76.

19 Kintsugi: The Art of Broken Pieces. Daiwa Anglo - Japanese Foundation. Prieiga per internetą: http://www.dajf.org.uk/event/kintsugi-the-artof-broken-pieces [žr. 201603 10] užuominoms, o užuominos yra japonu meno paslaptis. ${ }^{20}$ Kintsugi šiuo atveju yra tarsi erdvè tarp materialumo ir nematerialumo. Laikinumo simbolis gyvybės prasme. Skilimas tarsi ženklina kūniškajją baigtị ir dvasios gimtiz, jis suteikia ypatingo intymumo išgyvenimą ir puikiai iliustruoja mushin - neprieraišumo filosofiją, kurios taip trūksta mūsų kasdienybei.

Christy Bartlett, A Tearoom View of Mended Ceramics. The Aesthetics of Mended Japanese Ceramics. New York: Herbet F. Johnson Museum of Art, Cornell University, 2008.

Daisetz Teitaro Suzuki, Zen Buddhism and its influence on Japanese culture. Kyoto: The Eastern Buddhist Society, 1996.

Kintsugi: The Art of Broken Pieces. Daiwa Anglo Japanese Foundation. Prieiga per internetą: http://www.dajf.org.uk/event/kintsugi-the-artof-broken-pieces

Urushi: Japanese lacquer enchantment. Dentsdelion Antiques, 2012 rugsejjo-spalio mèn.

10 Urushi: Japanese lacquer enchantment. Dentsdelion Antiques, 2012 rugsejjo-spalio mèn.

11 Kintsugi: The Art of Broken Pieces.

12 Charly Iten, Ceramics Mended with Lacquer Fundamental Aesthetic Principle, Techniques and Artistic Concepts. The Aesthetics of Mended Japanese Ceramics. New York: Herbet F. Johnson Museum of Art, Cornell University, 2008, p. 20.

13 Charly Iten, p. 18.

14 Christy Bartlett, p. 8.

15 Christy Bartlett, A Tearoom View of Mended Ceramics. The Aesthetics of Mended Japanese Ceramics. New York: Herbet F. Johnson Museum of Art, Cornell University, 2008, p. 12.

16 Ten pat, p. 13.

17 Allen S. Weiss, p. 142.

18 Charly Iten, p. 23.

19 Allen S. Weiss, p. 141.

20 Daisetz Teitaro Suzuki, p. 148. 